AJCEM LIFE LINE CO. LTD.

Publishers of

AFRICAN JOURNAL OF CLINICAL AND EXPERIMENTAL MICROBIOLOGY (AJCEM)

Plot 708 Cassava Street

Wuye, Abuja, 900003

F.C.T. Nigeria

Our Ref: $\quad$ AJCEM/CL/FR/211

$11^{\text {th }}$ Feb, 2014

Content and Communications Manager,

PO Box 420,

Grahamstown 6140

South Africa.

Madam,

\title{
RETRACTION OF AN ARTICLE
}

There has been a credible complaint that the article, whose abstract is reproduced below, has been plagiarized. We are therefore requesting you to please retract the article from our website with immediate effect. A retraction notice should also be put in place so that readers may not cite it in future.

Thanking you for your usual cooperation

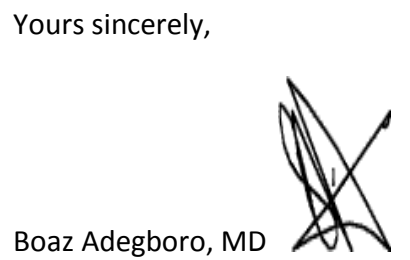

AJCEM Officer's Signature S

\section{ORIGINAL ARTICLE}

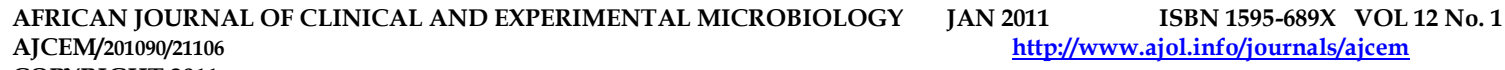

AFR. J. CLN. EXPER. MICROBIOL. 12(1): 26-31

INFLUENCE OF PHENOTYPES ON IMMUNITY TO PLASMODIUM FALCIPARUM MALARIA AMONG WOMEN IN PARTS OF THE IMO RIVER BASIN, NIGERIA. 
Chukwuocha, U.M. ${ }^{1}$, Dozie, I.N.S. ${ }^{2}$, Ashiegbu, K.K. ${ }^{3}$, Onwuliri, C.O.E. ${ }^{4}$, Aguwa, O.C. ${ }^{1}$, Nwoke E.A., Udujih O.G., Nwokoro J.C., Nwawume I.C.

1. Department of Public Health Technology, Federal University of Technology, Owerri, Imo State, Nigeria, 2. Department of Microbiology, Imo State University, Owerri, Imo State, Nigeria, Internal medicine unit, Federal Medical Centre, Owerri, Imo State, Nigeria, and Department of Biotechnology, Federal University of Technology, Owerri, Imo State, Nigeria.

Correspondence: Chukwuocha U.M. Department of Public Health Technology, Federal University of Technology, Owerri, Imo State, Nigeria. chukwuochauchem@yahoo.com +2348034712957

\begin{abstract}
This study analyses the association between $\mathrm{ABO}$ blood group phenotypes in relation to placental malaria pathology and birth outcomes in the lower Imo river Basin, Nigeria. A cross-sectional study of 647 mother/child pairs delivering in Aboh Mbaise General Hospital, Aboh Mbaise Local Government Area between February-June 2007 and January-July 2008 was undertaken. Maternal peripheral and cord blood samples were obtained at delivery. Placental tissue was obtained and malaria histology classified as active, past or no malaria infection. Birth anthropometry was recorded. ABO blood group was measured by agglutination.Results showed that in primiparae, blood group $\mathrm{O}$ was significantly associated with increased risk of active placental infection (OR 2.18, 95\% CI 1.15-4.6, p = 0.02) and an increased foetal-placental weight ratio compared to non-O phenotypes $(5.68$ versus $5.45, p=0.03)$. In multiparae blood group $\mathrm{O}$ was significantly associated with less frequent active placental infection (OR $0.59,95 \%$ CI $0.36-0.98, \mathrm{p}=0.04$ ), and a higher newborn ponderal index compared to non-O phenotypes ( 2.65 versus $2.55, p=0.007)$. In multivariate regression parity was independently associated with increased risk of placental malaria (active and past infection) in primiparae with blood group $O(p=0.034)$ and reduced risk in multiparae with the same phenotype $(p=0.015)$. Parity related susceptibility to placental malaria is associated with the mothers ABO phenotype. This interaction influences foetal and placental growth and could be an important modifying factor for pregnancy outcomes. The biological explanation could relate to sialic acid dependent placental membrane differences which vary with $\mathrm{ABO}$ blood group.
\end{abstract}

KEYWORDS: Malaria, Parity, Immunity, Phenotype, Pondera index, Placenta. 